\title{
Chemische Untersuchung der australischen Myrthe
}

(Engenia i. Jambosa australis).

Von de Luca und Ubaldini.

Die australische Myrthe hat nach einer speciellen Untersuchung von de Candolle den Namen Jambosa 8. Eugenia australis erhalten. Dieses Gewächs, welches im Freien und ohne besondere Cultur zu beanspruchen in dem botanischen Garten von Neapel wächst, erreicht eine Höhe von etwa 12 Meter, von dem cylindrischen und geraden Stamme gehen zahlreiche Aeste aus, welche dicht bedeckt sind von länglichen, dunkelgrünen Blättern; an den Spitzen der jungen Zweige und an den Ansatzstellen der Blätter treten weissliche Blüthen auf, welchen schön violett rothe Früchte folgen von der Grösse unserer Kirsche, aber mit länglicher Form und angenehmem schwach säuerlich süssem Geschmacke. Fast immer, etwa während der 6 Monate von November bis Endo März, ist die Myrthe mit Blüthen und Früchten bedeckt, eine Seltenheit für diese Gegenden. Der aus den Früchton gepresste Saft ist schön violett roth, von sehr angenehmem und leicht sauerm Geschmacke, beim Concentriren und in der Ruhe setzt sich daraus krystallisirter Cremor tartari ab; der Saft enthält Zucker und gäbrt bei -gewöhnlicher Temperatur unter Entwickelung von Kohlensäure und Bildung von Alkohol, der in der gegohrenen Flüssigkeit bleibt und durch Destillation daraus erhalten werden kann. Der Farbstoff der Früchte und des Saftes ist leicht löslich in Wasser und Alkohol, weniger löslich in einer Mischung von Alkohol und Aether, unlöslich in reinem Aether. Gereinigte Knochenkoble hält ihn zurück, wie es auch bei Traubenmost und Rothwein der Fall ist. Luft und Gährung verändern die violettrothe Farbe in weinroth, Säuren machen sie roth, Alkalien schön grün. Mit diesem Safte getränktes Papier, unter Luftabschluss aufbewahrt, zeigt sehr scharf freie Säure und freies Alkali an. Reducirende Stoffe, wie Alkohol-Aether, Schwefelwasserstoff, mehr noch Wasserstoff in stat. nase. entfärben den Myrthenfruchtsaft, der an der Luft wieder seine erste Farbe annimmt. Ëbenso verhält sich gegen Wasserstoff der Weinfarbstoff und Lackmus.

Rothwein und Myrthenfruchtsaft werden durch essigsaures Bleioxyd gefällt; zersetzt man die gefärbten Niederschläge in Gegenwart von Aether mit verdünnter Salzsäure, so bildet sich ein weisser Niederschlag von Chlorblei und zwei verschiedene Schichten: eine wässrige, welche den Farbstoff 
gelöst enthält, und eine farblose ätherische Schicht. Auf Zusatz von etwas Alkohol löst sich der Farbstoff des Rothweins und auch der Myrthenfrucht in dieser Mischung von Alkohol und Aether. Bringt man den Fruchtbrei in eine durch Quecksilber abgesperrte Röhre, die auch otwas Luft enthält, so geht die Gährung vor sich unter Entwickelung von Kohlensäure und Bildung von Alkohol; dann tritt saure Gährung ein. Bis zur Beendigung der Gährung vergehen mehre Wochen; schüttelt man jedoch die, zerquetschten Früchte mit Luft, so vollendet sich die Gährung in wenigen Stunden bis zur Umwandlung des Alkohols in Essigsäure. Der ausgegohrene Myrthenfruchtsaft ist der Myrthenwein, der mit der Zeit ein sehr angenehmes, ätherisches Bouquet gewinnt; der nicht gegohrene Saft giebt beim Eindampfen eine syrupartige, zuckerhaltige Masse, wie man sie auch aus Traubenmost erhält. Der bis auf $1 / 10$ Volumen eingedampfte Myrthenwein setzt nach 24 stündiger Ruhe Cremor tartari ab. Schüttelt man den Wein mit dem doppelten Volumen einer Mischung von Alkohol und Aether zu gleichen Theilen, so setzen sich nach 24 Stunden kleine Krystalle von Cremor tartari an die Wände des gut verschlossenen Gefässes. Ausser Cremor tartari enthält dieser Wein freie Weinsäure, die man durch alkoholisirten Aether fällen kann, nachdem man sie durch Zusatz von etwas Kali in Bitartrat umgewandelt bat.

Diese Resultate sprechen für eine innige Beziehung zwischen Weintraube und Myrthenfrucht. Man findet in Sicilien hänfig eine Myrthe mit weissen, zuckerhaltigen Früchten, die man mit den weissen Trauben vergleichen kann, und die auch einen Wein liefern, welcher Cremor tartari und freie Weinsäure enthält. Wahrscheinlich würde sich diese so nutzbare Myrthe auch nach einigen Gegenden des südlichen Frankreich verpflanzen lassen wo sie sich ebenso acclimatisiren würde, wie durch die Bemühungen des Directors des botanischen Gartens zu Neapel Gasparini in Norditalien. (Journ. de Pharm. et d. Chim.).

Dr. Reich.

\section{Ueber Selerotien.}

In der Versammlung des Naturforschenden Vereins in Brün, October 1867, wurden mehre ausgetrocknete Wurzelstöcke von Kümmel (Carum Carvi) vorgezeigt, in deren Innern sich grosse harte Gebilde in verschiedenen Formen entwickelt 